\title{
Scapular Glenoid Cavity in Central Indian Population: A Morphological Study
}

\section{ABSTRACT}

Introduction: The Glenoid Cavity (GC) of scapula has highly variable morphology. The rim of GC presents a notch in its upper and front part, because of this glenoid notch, various shapes of GC are found like pear, oval or inverted comma shaped. For total shoulder arthroplasty, knowledge of the shape and dimensions of the glenoid are important in the design and fitting of glenoid component. Various anatomical parameters of the glenoid like height, width, articular surface area, inclination, vault size and shape are relevant for prosthesis design. There is considerable natural variability in these parameters. Anatomical variations of GC are also important for understanding the various pathologies involving the shoulder joints. The present study tries to determine the measurements of various dimensions of the GC including the variations in its shape and surface area.

Aim: To obtain the morphometric data and various shapes of the GC relevant to the central Indian population and to compare the data obtained from the present study with previous studies.

Materials and Methods: The study was carried out on $150 \mathrm{dry}$, adult human scapulae of unknown sex, collected from the museum of Department of Anatomy, out of which, 67 were of right side and 83 of left side belonging to central Indian population of unknown sex and age. Morphological evaluation and morphometric measurements for GC were done in each scapula using digital vernier calliper. The height and anteroposterior diameter of the GC was measured at three different levels. Shape of the GC, based on the presence of a notch on the anterior glenoid rim, was noted as pear, oval or inverted comma shape.

Results: The mean Superior-inferior (SI) diameter of the GC was observed as $33.84 \pm 3.08 \mathrm{~mm}$ on right side and $33.68 \pm 2.75 \mathrm{~mm}$ on left side. The mean Anterior Posterior 1 was $23.65 \pm 3.47$ and $23.60 \pm 2.79$ on right and left side, respectively. Anterior Posterior 2 was $14.98 \pm 2.41$ and $14.16 \pm 2.23$ on right and left side, respectively, whereas, Anterior Posterior 3 were $19.12 \pm 3.59$ and $18.44 \pm 3.11$ on right and left side, respectively. A 33.3\% glenoid cavities were oval shaped, $50.66 \%$ were of pear shape and $16 \%$ were of inverted comma shape.

Conclusion: The present study can be helpful to orthopaedic surgeons and biomechanical engineers during designing and fitting the implants for total shoulder arthroplasty. The size of the GC is known to be variable in different population. Hence, while designing the glenoid component of the prosthesis; smaller dimensions of the glenoid cavities in Indian population should be considered.

\section{INTRODUCTION}

The scapula is a large, flat, triangular bone lying on the posterolateral aspect of the chest wall, covering parts of second to seventh rib [1]. Lateral border of the scapula ends superiorly at GC which articulates with the head of the humerus to form gleno-humeral joint [2]. The articular surface of GC is pear shaped, its inferior half is $20 \%$ larger than the superior half [3]. The GC has highly variable morphology. The rim of GC presents a notch in its upper and front part [4]. Because of presence of this glenoid notch, various shapes of GC are found like pear-shaped, oval or inverted comma shaped $[5,6]$. For total shoulder arthroplasty, knowledge of the shape and dimensions of the glenoid are important in the design and fitting of glenoid component. Various anatomical parameters of the glenoid like height, width, articular surface area, inclination, vault size and shape are relevant for prosthesis design. There is considerable natural variability in these parameters, and this has been demonstrated by many cadaveric studies. The prosthesis design, instrumentation and intraoperative implantation techniques are affected by this variability [7]. The variations in the shape and size of GC and attachment of glenoid labrum at the glenoid notch are important for normal functioning of this most freely movable joint of the human body. In comma shaped GC, the glenoid labrum is not firmly attached to the margins of GC. This arrangement simulates a labral tear, sublabrum foramen or Buford complex during arthroscopy. The shoulder joint is the most frequently dislocated joint in the body and dislocations of shoulder joint with fractures of the GC are also quite common in trauma. An understanding of variations in normal anatomy of GC is essential while evaluating pathological conditions like osseous Bankart lesion and osteochondral defects $[7,8]$. A proper understanding of the anatomic and prosthetic variables involved with glenoid replacement allows shoulder surgeons to provide their patients the best opportunity for a positive outcome after Total Shoulder Arthoplasty (TSA). Similarly the knowledge of the normal GC morphometry is of great significance to sports medical professionals and its anthropometry cannot be overlooked by anatomist and medicolegal forensic experts. The restoration of normal anatomy is the goal in orthopaedic surgery [9]. The purpose of the present study was to obtain the morphometric data and various shapes of the GC relevant to better understand the biomechanics of the reconstructed glenohumeral joint and and to identify the factors that contribute to glenoid component loosening and ongoing variations, variations in component design and fixation, the mechanisms of glenoid loosening, the outcomes of revision surgery in the treatment of glenoid component failure, and alternative treatments for younger patients among the central Indian population and to compare the data obtained from the present study with previous studies.

\section{MATERIALS AND METHODS}

An observational cross-sectional (morphological) study was conducted in the Department of Anatomy, Government Medical College, Nagpur, India. The study was done through the year from January to December 2019 after taking the ethical clearence from the Instutional Ethics Committee (No.229/EC/Pharmac/GMC/NGP/). 
Inclusion and Exclusion criteria: The present study included 150 adult dry scapulae which were available in the museum of Department of Anatomy, collected by convenience sampling. Out of these, 67 belonged to right side and 83 to left side belonging to central Indian population of unknown sex and age. Broken, damaged or scapulae showing degenerative changes were excluded from the study.

Morphological evaluation and morphometric measurements of GC were done in each scapula. All linear measurements (in millimeters) were ascertained by using digital vernier calliper (accuracy $0.01 \mathrm{~mm}$ ) [Table/Fig-1-5]. The following parameters were studied:
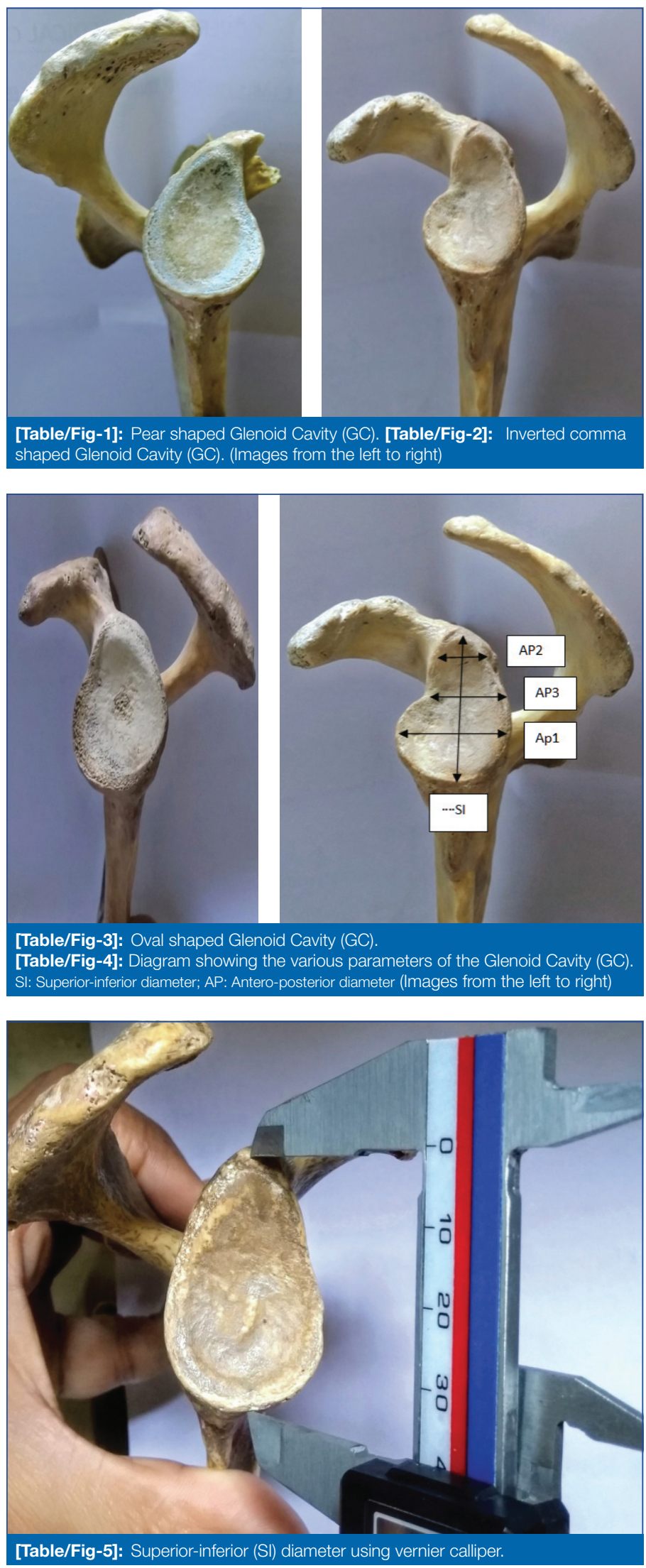

Superior-inferior glenoid diameter (SI): It is described as the maximum distance from the inferior point on the glenoid margin to the most prominent point of the supra-glenoid tubercle [10]

Anterior-posterior glenoid diameter (AP): The width of the glenoid was measured at three different levels. Anteroposterior diameter (AP1) was measured as the maximum breadth perpendicular to the height of glenoid in the lower half. Anteroposterior diameter (AP2) was measured as breadth of upper half of the GC midway between superior margin and midequater. The diameter at the level of the peak of the glenoid notch, when present, was also measured (AP3) [10].

Shape of the Glenoid Cavity (GC): It was noted whether the GC was inverted comma shaped, oval or pear shaped [10].

\section{STATISTICAL ANALYSIS}

The mean, standard deviation, range and asymmetry in bilateral parameters were calculated using Graphpad prism software for the data. The $p$-values $<0.05$ were considered significant

\section{RESULTS}

The measurements of the GC were taken in total of 150 scapulae, of which 67 were of right side and 83 of left side as shown in [Table/ Fig-6]. The SI diameter of the GC ranged between 27.47-41.20 mm on the right side and between $27.5-39.58 \mathrm{~mm}$ on the left side. It was observed that the AP1 glenoid diameter of the right side ranged between 14.78-30.65 $\mathrm{mm}$ and that of left side ranged between 15.45-29.02 mm. The AP2 glenoid diameter of right and left side ranged between 10.22-19.34 mm and 10.66-19.45 mm. It was observed that the AP3 glenoid diameter of the right side ranged between 13.38-30.02 mm and on left side it was 12.54-25.33 mm.

\begin{tabular}{|l|c|c|c|c|c|c|}
\hline \multirow{2}{*}{ Parameter } & \multicolumn{2}{|c|}{ Range (in mm) } & \multicolumn{2}{c|}{ Mean \pm Std. Dev } & \multicolumn{2}{c|}{$p$-value } \\
\cline { 2 - 7 } & $\begin{array}{c}\text { Right } \\
(\mathrm{n}=67)\end{array}$ & $\begin{array}{c}\text { Left } \\
(\mathrm{n}=83)\end{array}$ & Right & Left & Right & Left \\
\hline SI diameter & $\begin{array}{c}27.47- \\
41.20\end{array}$ & $\begin{array}{c}27.45- \\
39.58\end{array}$ & $33.84 \pm 3.08$ & $33.68 \pm 2.75$ & 0.9375 & 0.7957 \\
\hline AP1 & $\begin{array}{c}14.78- \\
30.65\end{array}$ & $\begin{array}{c}15.45- \\
29.02\end{array}$ & $23.65 \pm 3.47$ & $23.60 \pm 2.79$ & 0.1600 & 0.5267 \\
\hline AP2 & $\begin{array}{c}10.22- \\
19.34\end{array}$ & $\begin{array}{c}10.66- \\
19.45\end{array}$ & $14.98 \pm 2.41$ & $14.16 \pm 2.23$ & 0.0151 & 0.0143 \\
\hline AP3 & $\begin{array}{c}13.38- \\
30.02\end{array}$ & $\begin{array}{c}12.54- \\
25.33\end{array}$ & $19.12 \pm 3.59$ & $18.44 \pm 3.11$ & 0.0551 & 0.0797 \\
\hline
\end{tabular}

The shape of the GC was observed, out of the 67 scapulae of the right side, 20 (31.74\%) were oval shaped, 34 (53.96\%) were pear shaped and $13(20.63 \%)$ had inverted comma shaped GC. Out of the 83 scapulae of the left side, $30(34.48 \%)$ were oval shaped, 42 (48.27\%) were pear shaped and 11 (12.64\%) had inverted comma shaped GC as shown in [Table/Fig-7].

\begin{tabular}{|l|c|c|}
\hline \multirow{2}{*}{ Shape of glenoid cavity } & \multicolumn{2}{|c|}{ Incidence of shape (percentage) } \\
\cline { 2 - 3 } & Right & Left \\
\hline Oval & $20(29.85)$ & $30(36.14)$ \\
\hline Pear & $34(50.74)$ & $42(50.60)$ \\
\hline Inverted comma & $13(19.40)$ & $11(13.25)$ \\
\hline \multicolumn{2}{|l|}{ [Table/Fig-7]: Comparison of shapes of right and left Glenoid Cavity (GC). }
\end{tabular}

\section{DISCUSSION}

An accurate knowledge of normal and variational anatomy of the scapula is of great importance, in order to avoid complications when procedures are performed via open, arthroscopic, or arthroscopically assisted method adjoining shoulder region as well as for obtaining precise congruency of the glenohumeral joint after total shoulder arthroplasty $[2,3,6]$. It has already been studied by many authors and was also performed in various ways including direct measurements of dry scapula, direct measurements of fresh or embalmed cadavers, radiographic measurements of scapula or radiographic measurements 


\begin{tabular}{|c|c|c|c|c|c|c|c|c|c|}
\hline \multirow[b]{2}{*}{ Author } & \multirow[b]{2}{*}{ Year } & \multirow{2}{*}{$\begin{array}{c}\text { No. of } \\
\text { specimen }\end{array}$} & \multicolumn{3}{|c|}{ Shape of glenoid cavity } & \multirow{2}{*}{$\begin{array}{l}\text { Mean SI diameter } \\
(\mathrm{mm})\end{array}$} & \multirow{2}{*}{$\begin{array}{l}\text { AP1 diameter } \\
(\mathrm{mm})\end{array}$} & \multirow{2}{*}{$\begin{array}{l}\text { AP2 diameter } \\
(\mathrm{mm})\end{array}$} & \multirow{2}{*}{$\begin{array}{l}\text { AP3 diameter } \\
(\mathrm{mm})\end{array}$} \\
\hline & & & Pear & Oval & Inverted-comma & & & & \\
\hline \multirow{2}{*}{ Mamatha T et al., [13] } & \multirow{2}{*}{2011} & Rt. 98 & 46 & 20 & 34 & $33.67 \pm 2.82$ & $23.35 \pm 2.04$ & $16.27 \pm 2.01$ & \multirow{2}{*}{--} \\
\hline & & Lt 104 & 43 & 24 & 33 & $33.92+2.87$ & $23.05+2.30$ & $15.77+1.96$ & \\
\hline \multirow{2}{*}{ Rajput HB et al., [14] } & \multirow{2}{*}{2012} & Rt 43 & 49 & 16 & 35 & $34.76+3.0$ & $23.31+3.0$ & $15.10+2.54$ & $16.2 \pm 3.23$ \\
\hline & & Lt 57 & 46 & 15 & 39 & $34.43+3.21$ & $22.92+2.80$ & $13.83+2.45$ & $15.24 \pm 2.04$ \\
\hline \multirow{2}{*}{ Gosavi SN et al., [16] } & \multirow{2}{*}{2014} & Rt 62 & 54.83 & 32.25 & 12 & $35.03 \pm 5.25$ & $24.17 \pm 2.57$ & $14.56 \pm 2.03$ & $17.72 \pm 1.89$ \\
\hline & & Lt 80 & 45 & 43.75 & 11.2 & $35.3 \pm 3.41$ & $23.9 \pm 2.66$ & $14.6 \pm 1.85$ & $16.82 \pm 2.18$ \\
\hline \multirow{2}{*}{ Sarwar MS et al., [17] } & \multirow{2}{*}{2015} & Rt 50 & 56 & 20 & 24 & $35.22+3.26$ & $23.95+2.78$ & $16.16+2.38$ & \\
\hline & & Lt 50 & 64 & 16 & 20 & $34.53+3.21$ & $23.64+2.37$ & $15.34+2.17$ & \\
\hline \multirow{2}{*}{$\begin{array}{l}\text { Wael Amin el din and } \\
\text { Mona Hassan MA [18] }\end{array}$} & \multirow{2}{*}{2015} & Rt 80 & 35 & 48.75 & 16.25 & $38.88+2.63$ & $21.33+2.06$ & $28.31+2.38$ & \\
\hline & & Lt 80 & 27.5 & 52.50 & 20 & $39.01+2.49$ & $21.69+2.06$ & $27.99+2.55$ & \\
\hline \multirow{2}{*}{ Tiwari $\vee$ et al., [19] } & \multirow{2}{*}{2018} & Rt 100 & 51 & 19 & 30 & $35.94+2.30$ & $24.37+2.34$ & $16.62+2.82$ & \\
\hline & & Lt 106 & 49.04 & 19.82 & 31.14 & $35.68+2.14$ & $24.20+2.28$ & $16.14+2.84$ & \\
\hline \multirow{2}{*}{ Present study } & \multirow{2}{*}{2020} & Rt 67 & 34 & 20 & 13 & $33.84 \pm 3.08$ & $23.65 \pm 3.47$ & $14.98 \pm 2.41$ & $19.12 \pm 3.59$ \\
\hline & & Lt 83 & 42 & 30 & 11 & $33.68 \pm 2.75$ & $23.60 \pm 2.79$ & $14.16 \pm 2.23$ & $18.44 \pm 3.11$ \\
\hline
\end{tabular}

in living patients. The present study has been correlated with the other studies for any similarity or difference.

Recently, Poppen NK and Walker PS, emphasised that abnormal morphology of the glenoid is associated with severe full thickness tears [12]. There is significant difference in the size in different parts of the world as shown in [Table/Fig-3]. The length of GC is an important factor which should be appropriately matched with the size of prosthesis during total shoulder arthroplasty in order to achieve full congruency $[2,7,11,12]$. Previous studies done on matched cadaveric pairs showed that only a little variance exists between men and women, but the differences between races are considerable [6].

The present study was performed on dry adult human scapulae and after taking the morphometric parameters of the GC, the results were compared with the results of the other studies [Table/Fig-8] [13-19]. Present findings indicate that the most common glenoid type is pear shaped while the least one is inverted comma shaped. These results are in symmetry with Mamatha T et al., Rajput HB et al., and Sarwar MS et al., which also showed that most common glenoid is pear shaped $[13,14,17]$. Coskun $\mathrm{N}$ et al., reported oval shaped glenoid to be more common (72\%) in Turkish population [2] while Gamal Hamed ESH, found inverted comma shaped glenoid in $30.88 \%$ of Egyptians [20]. They explained that in the area of the glenoid notch, the labrum is not fixed to bony margins of GC but bridges the notch itself. Such an attachment of glenoid labrum makes the shoulder joint less resistant to dislocating forces, tear and avulsions. This means one third of Egyptian population were prone to the Bankart lesion [20]. In the present study, the average SI diameter of the right glenoid was $33.84 \pm 3.08 \mathrm{~mm}$ and the average $\mathrm{SI}$ diameter of the left glenoid was $33.68 \pm 2.75 \mathrm{~mm}$. Although the right glenoid SI diameter was slightly more than the left, it was not statistically significant. Mamatha T et al., and Rajput HB et al., also measured the SI diameter of right and left side separately $[13,14]$ and the present readings were nearest to the readings of Mamatha T et al., [13]. In present study, mean AP1 of the glenoid was also close to the results of Mamatha T et al., Rajput HB et al., Gosavi SN et al., and Sarwar MS et al., [13,14,16,17]. Wael Amin NED and Mona Hassan MA, reported lower [18] and Kavitha P et al., and Tiwari $V$ et al., found higher values as compared to the present study $[15,19]$. The AP2 diameter coincided with the study of Gosavi $\mathrm{SN}$ et al., [16]. These values of present study are less than Mamatha T et al., Rajput HB et al., Kavitha $\mathrm{P}$ et al., Sarwar MS et al., Wael Amin NED and Mona Hassan MA, and Tiwari V et al., [13-15,1719]. The AP3 diameter in the present study was higher than Rajput HB et al., and Gosavi SN et al., [14,16]. Mamatha T et al., stated that, there was no priority of the side for the glenoid notch, so that an influence of handedness on the shaping of the GC is unlikely [13]. Akhtar MJ et al., observed that, in south India, 16.5\% of type 2 diabetes mellitus patients suffered from frozen shoulder, $5.48 \%$ from periathritis of the shoulder joint and $3.55 \%$ from rotator cuff injury [21]. An increase in the aging population accompanied by an increase in the incidence of type 2 diabetes mellitus indicates that arthritic disease of the shoulder may become more common in the near future [10]. It has also been observed that, the shoulder is the third most common large joint to require surgical reconstruction, after the knee and hip [12]. Shewale SN et al., found that prosthesis required for female patients should be of smaller size than that for male patients and further these values can also help in determination of gender from scapulae of unknown deceased residuals particularly in medico legal cases [22]. The study of Yadav $Y$ et al., and Singh A et al., also found same findings and were helpful to understand the shoulder pathology better [23,24]. On comparing data of the present study with that obtained by several authors, several differences as well as similarities in the measurements of scapula and GC were observed. This may be due to population variation and measurement techniques.

\section{Limitation(s)}

In the present study, variations of GC with respect to age and sex have not been studied. Another limitation includes its small sample size. Further morphological studies with large sample size can be done for evaluating different variations of GC.

\section{CONCLUSION(S)}

The knowledge about the different shapes and dimensions of GC could be useful during evaluation and management of defects and lesions of glenoid. The present study may be helpful for biomechanical engineers and orthopaedic surgeons during designing and fitting the implants for total shoulder arthroplasty. Size of the GC is known to be variable in different populations. Hence, while designing the glenoid component of the prosthesis; the smaller dimensions of the glenoid cavities in Indian population should be considered. The present study concludes that the shape and size of GC do not only vary in races but also in same population. Hence, this information is valuable for the surgeons during operations around shoulder joint.

\section{REFERENCES}

[1] Johnson D. Pectoral Girdle, Shoulder region and Axilla. In: Standring S, Borley NR, Collins P, Crossman AR, Gatzoulis MA, Healy JC, et al, editors. Gray's Anatomy, The Anatomical Basis of Clinical Practice. $40^{\text {th }}$ ed. Churchill Livingstone; 2013. Pp. 791-822.

[2] Coskun N, Karoali K, Cevikol C, Demirel MB, Sindel M. Anatomical basis and variations of the scapula in Turkish adults. Saudi Medical Journal. 2006;27(9):1320-25. 
[3] TWilk KE, Arrigo CA, Andrew JR. Current concepts: The stabilizing structures of Glenohumeral joint. Journal of Othropaedicand Sports physical therapy. 1997;25(6):364-79.

[4] Breathnach AS. Frazer's Anatomy of the Human Skeleton. $6^{\text {th }}$ ed. London: J and A Churchill Ltd; 1965. Pp. 63-70.

[5] Prescher A, Klumpen T. The glenoid notch and its relation to the shape of the glenoid cavity of the scapula. J Anat. 1997;190(3):457-60.

[6] Churchill RS, Brems JJ, Kotschi H. Glenoid size, inclination, and version: An anatomic study. J Shoulder Elbow Surg. 2001;10(4):327-32.

[7] Strauss EJ, Roche C, Flurin PH, Wright T, Zuckerman JD. The glenoid in shoulder arthroplasty. J shoulder Elbow Surg. 2009;18:819-33.

[8] Tulte JM, Blankenbaker DG, Selfert M, Zlegert AJ, Orwin JF. Sublabral foramen and Buford complex: Inferior extent of unattached or absent labrum in 50 patients. Radiology. 2002;223(1):137-14.

[9] Mathew AJ, Nair JB, Pillai SS. Rheumatic musculoskeletal manifestations in type 2 diabetes mellitus in south India. Int J Rheum Dis. 2011;14:55-60.

[10] Dhindsa GS, Singh Z. A study of morphology of glenoid cavity. Jr of Evolution of Medical and Dental sciences. 2014;3:7036-43.

[11] Kandemir V, Allaire RB, Jolly JT, Debski RE, McMohan PJ. The Relationship between the orientation of the glenoid and tears of the rotator cuff. JBJS. 2006;88(8):1105-09.

[12] Poppen NK, Walker PS. Normal and abnormal motion of the shoulder. Journal of Bone and Joint Surgery. 1976;58:195-201.

[13] Mamatha T, Pai SR, Murlimanju BV, Kalthur SG, Pai MM, Kumar B. Morphology of glenoid cavity. Online J health Allied Scs. 2011;10(3):7.

[14] Rajput HB, Vyas KK, Shroff BD. A study of morphological patterns of the glenoid cavity of scapula. National J of Medical Research. 2012;2(4):504-07.

[15] Kavitha P, Jaskaran S, Geeta. Morphology of coracoids process and glenoid cavity in adult human scapulae. IJAPBS. 2013;2(2):19-22.
[16] Gosavi SN, Jadhav SD, Garud RS. Morphometric study of Scapular glenoid cavity in Indian population. IOSR Journal of Dental and Medical Sciences (IOSRJDMS). 2014;13(9):67-69.

[17] Sarwar MS, Diwan CV, Rahamn H, Raheman H, Moosa SM. A Morphometeric study of glenoid cavity of adult human scapula. International Journal of Recent Trends in Science and Technology. 2015;15(3):486-90.

[18] Wael Amin NED, Mona Hassan MA. A morphometric study of the patterns and variations of the acromion and glenoid cavity of the scapulae in Egyptian population. Journal of Clinical and Diagnostic Research. 2015;9(8):08-11.

[19] Tiwari V, Das SS, Vasudeva N. Geometric morphometry of glenoid cavity in dry adult scapula and its surgical implications. International Journal of Scientific Research. 2018;7(1): ISSN No 2277-8179.

[20] Gamal Hamed ESH. Morphometry of glenoid fossa in adult Egyptian scapulae. Int J Anat Res. 2015;3(2):1138-42.

[21] Akhtar MJ, Kumar B, Fatima N, Kumar V. Morphometric analysis of glenoid cavity of dry scapulae and its role in shoulder prosthesis. Int J Res Med Sci. 2016;4(7):2770-76.

[22] Shewale SN, Laeeque Md, Sukre SB, Patil SC. Morphometric study of glenoid cavities of scapulae in marathwada population. Int J Anat Res 2017;5(2.1):375965. ISSN 2321-4287

[23] Yadav Y, Potdar P, Dhakar J. Morphometric study of glenoid cavity of scapulae in north Indian population with clinical significance. Santosh University Journal of Health Sciences. 2019;5(2):78-81.

[24] Singh A, Singh A, Agarwal P, Gupta R. A morphological and morphometric study of glenoid fossa of scapula and its implication in shoulder arthroplasty. International Journal of Anatomy, Radiology and Surgery. 2019;8(3):AO06-09.

PARTICULARS OF CONTRIBUTORS:

1. Associate Professor, Department of Anatomy, GMC, Nagpur, Maharashtra, India.

2. Associate Professor, Department of Anatomy, GMC, Nagpur, Maharashtra, India.

3. Professor, Department of Anatomy, K.M. Medical College, Mathura, Uttar Pradesh, India.

NAME, ADDRESS, E-MAIL ID OF THE CORRESPONDING AUTHOR:

Dr. Rajeshree N Dange,

34/A, RBI Colony, Near NIT Garden, Katol Road, Nagpur-13, Maharashtra, India.

E-mail: rajeshreedng@yahoo.com
PLAGIARISM CHECKING METHODS: JJain Het al.]

- Plagiarism X-checker: Jun 08, 2020

- Manual Googling: Aug 12, 2020

- iThenticate Software: Jun 16, $2021(18 \%)$
ETYMOLOGY: Author Origin

\section{AUTHOR DECLARATION:}

- Financial or Other Competing Interests: None

- Was Ethics Committee Approval obtained for this study? Yes

- Was informed consent obtained from the subjects involved in the study? NA

- For any images presented appropriate consent has been obtained from the subjects. NA
Date of Submission: Jun 06, 2020 Date of Peer Review: Jul 17, 2020 Date of Acceptance: Sep 07, 2020 Date of Publishing: Jul 01, 2021 